\title{
PORTABLE SUSPENSION FRAME
}

\author{
By MISS P. CHATTERTON, M.C.S.P.
}

$\mathbf{T}$ REATMENT of patients in bed by sling suspension therapy usually presents a problem to the physiotherapist, due to the lack of portable suspension frames in most hospitals and institutions. The recognised models are extremely useful-they are light and easy to adjust but expensive if they are to be purchased in quantity.

Having worked for some time now with frames constructed locally to my own design of tubular steel piping and squared burglar-proof wire mesh, I find this type of frame preferable owing to the ease with which the points of suspension can be altered. Provided that the area of wire-mesh is large enough to cover the patient, the slings can be suspended from any required point, without moving patient or bed. The fixed type which $I$ have in use is $7 \mathrm{ft}$. high, and has an overhead frame $8 \mathrm{ft}$. $\times 5 \mathrm{ft}$., giving freedom for the physiotherapist to walk round the plinth, unhindered by the support of the frame. Hooks fixed in the wall are used for the attachment of springs or weights and pulleys for resistance.

The portable frame was constructed to fit the normal hcspital bed, so that when it is hooked over the lower rail of the bed at the head and the foot end, the overhead frame, which is $6 \mathrm{ft}$. $7 \frac{1}{2}$ ins. long and $2 \mathrm{ft}$. wide, is $7 \mathrm{ft}$. from the floor. If desired, the frame can be further secured

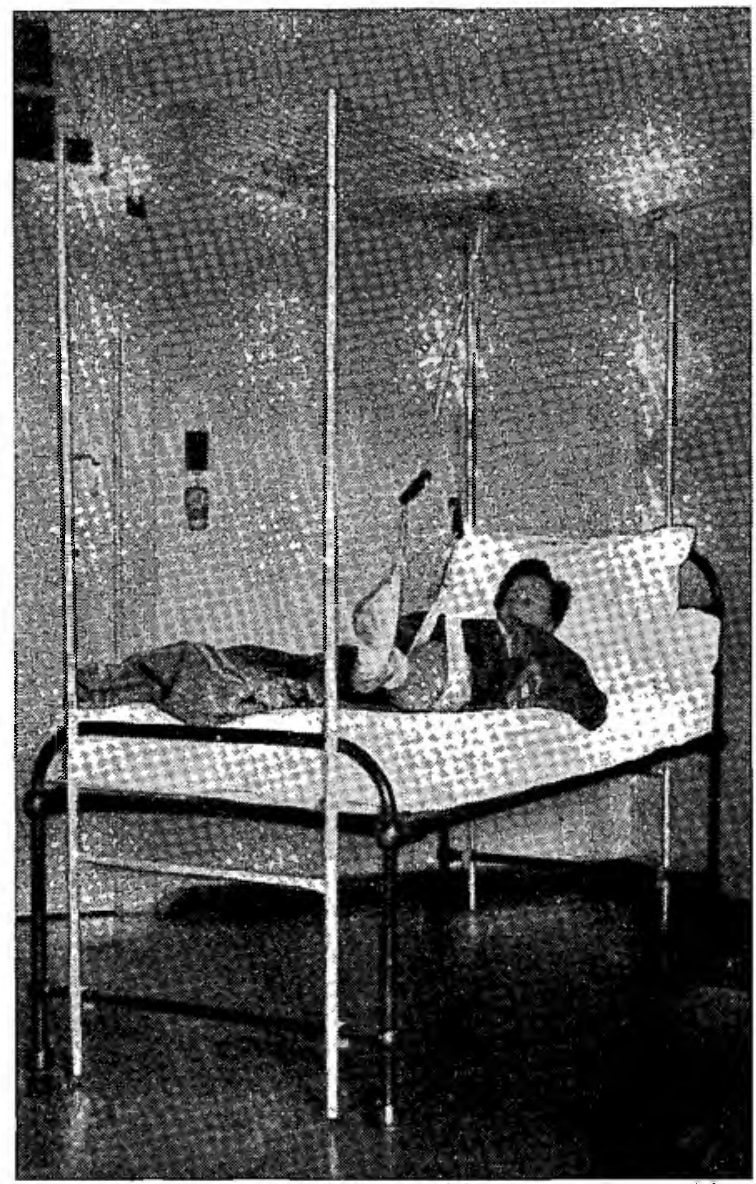

to the bed by $U$ hooks, passing through the upright poles and round the upper rail at the head and foot end of the bed, tightened with butterfly bolts. The upright poles are jointed 5 ins. from the top at one end, and 7 ins. from the top at the other end, so that the lower ends will swing inwards to fold upon one another. The frame can then easily be dismantled and transported, and when closed i. occupies a storage space of $6 \mathrm{ft}$. $7 \frac{1}{2}$ ins. $\times 24$ ins. $\times 7$ inst

When fixed on the patient's bed, it remains in position until otherwise required. The bed can be moved freely with no hindrance as the upright poles are 1 in. off the floor. In height the frame is low enough to allow patient, bed and frame to pass freely through a door onto the verandah. The frame does not interfere in any way with nursing. Extra holes can be drilled through the upright poles at convenient points for the attachment of hooks, springs, pulleys, etc.

The wire-mesh itself is naturally not strong enough to bear the weight of total suspension, but, should this be necessary, there is a cross-bar midway across the frame of $\frac{3}{4}$ in. tubular steel, which is adequate to bear the full weight of the pelvis. The uprights and the frame itself are also of $\frac{3}{4}$ in. tubular steel. The wire-mesh will take considerable strain, and will easily carry the weight of one or both legs, fully suspended, and even the strain of knee extension against $30 \mathrm{lb}$. springs.

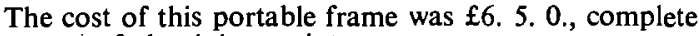
with a coat of aluminium paint.

\section{J. H. ISAACS \& CO. LIMITED}

(Established 1902)

\section{REAL ESTATE \& INSURANCE AGENTS}

Professional suites will be available for letting in a number of magnificent buildings now in the course of construction.

For further details please telephone 23-2561 or write to-

Century Insurance Building,

Corner Market \& Kruis Streets,

P.O. Box 5575. Johannesburg. 